\title{
Sobre os Direitos Naturais das Crianças \\ Uma Experiência com a Cozinha de Lama em uma Escola Infantil Brasileira
}

\author{
(4) Circe Mara Marques ${ }^{1,2}$ y Ana Paula de Lima Pires 3 \\ 1 Universidade Alto Vale do Rio do Peixe, Caçador, Brasil. \\ 2 Universidade Comunitária da Região de Chapecó, Chapecó, Brasil \\ Correo electrónico: circemaramarques@gmail.com \\ 3 Universidade Alto Vale do Rio do Peixe, Caçador, Brasil. \\ Correo electrónico: anapauladelimapires37@gmail.com
}

\section{Resumo}

Este artigo trata dos direitos naturais das crianças. O estudo teve como objetivo conhecer os modos de interações das crianças com os elementos da natureza durante a implementação um espaço de brincadeira no pátio de uma escola pública de educação infantil, localizada em um município da região Sul do Brasil. Metodologicamente a investigação consistiu em uma pesquisa-ação com a participação de 17 crianças de quatro a cinco anos. Ao longo da pesquisa as crianças participaram do planejamento, captação de recursos, construção e organização de uma 'cozinha de lama'. A implantação do espaço contou com apoio da equipe da Secretaria Municipal de Educação (SME), famílias e pequenos empresários locais. Os resultados mostraram que a relação das crianças com a natureza é atravessada tanto pelas experiências lúdicas com a terra e a água, como pela cumplicidade dos adultos, familiares e professores, na condição de mediadores positivos dessa relação.

\section{Sobre los Derechos Naturales de los Niños: una experiencia con la Cocina de Barro en una Escuela Infantil Brasileña}

\section{Resumen}

Este articulo aborda los derechos naturales de los niños. El estudio tuvo como objetivo comprender los modos de interacción de los niños con los elementos de la naturaleza durante la implementación de un espacio de juego en el patio de una escuela infantil pública, ubicada en un municipio de la región sur de Brasil. Metodológicamente la investigación consistió en una pesquisa-acción con 17 niños entre cuatro y cinco años. Durante la investigación, los niños participaron del planeamiento, captación de recursos, construcción y organización

Recibido:

1 de mayo de 2021 Aceptado:

17 de noviembre de 2021

doi: 10.34096/runa.v43i1.10165

Palavras-chave

Brincar; Educação infantil; Natureza; Direitos naturais

\section{Palabras clave}

Brincar; Educación infantil; Naturaleza; Derechos naturales 
de una "cocina de barro". La implementación del sitio ha contado con el apoyo del equipo de la Secretaria Municipal de Educación (SME), familias y pequeños empresarios locales. Los resultados mostraron que la relación de los niños con la naturaleza es atravesada tanto per las experiencias lúdicas con tierra y agua como per la complicidad de los adultos, parientes y profesores como mediadores positivos de esa relación.

\title{
Of Children's Natural Rights: An experience with a Mud Kit- chen in a Brazilian Children's School
}

\begin{abstract}
Key Words

Playing; Early childhood education; Nature; Natural rights

This paper addresses children's natural rights. The study aimed to understand the modes of interactions of children with the elements of nature during the implementation of a play space in the courtyard of a public kindergarten school, located in a municipality in the southern region of Brazil. In terms of methodology, the investigation consists of action research with 17 four- to fiveyear-old children. During the investigation, children participated in planning, fundraising, construction, and organising a 'mud kitchen'. Settlement of the space has gained aid from the Municipal Secretary of Education (SMED), families and small local businesspersons. Results showed that children's relation with nature is cut across by playful experiences with earth and water, as well as adult, family and teacher participation as positive mediators.
\end{abstract}

\section{Introdução}

Direitos Naturais das Crianças 1. Direito ao ócio:

A viver momento não programados pelos adultos.

2. Direito a se sujar:

A brincar com areia, terra, grama, folhas, água, pedras e galhos.

3. Direito aos odores:

A sentir os gostos dos aromas, reconhecer os perfumes oferecidos pela natureza.

4. Direito ao diálogo:

A ouvir e poder tomar a palavra, conversar e dialogar.

5. Direito a usar as mãos:

A bater pregos, serrar e raspar madeira, lixar, colar, modelar o barro, amarrar cordas, acender o fogo.

6. Direito a um bom início: comer comidas saudáveis desde o nascimento, beber água limpa e respirar ar puro.

7. Direito à rua:

brincar em praças e caminhar pelas ruas.

8. Direito ao selvagem:

A construir um refúgio de brincadeiras na mata, a ter bosques para se esconder, árvores para subir.

9. Direito ao silêncio:

A ouvir o soprar do vento, o canto dos passarinhos, o borbulhar da água.

10. Direito às nuances:

A ver a alvorada e o pôr do sol, admirar à noite, a lua e as estrelas.

(Zavalloni, 2012, p. 163) 
Iniciamos este escrito trazendo as palavras de Gianfranco Zavalloni (2012) que nos ensina sobre os Direitos Naturais das Crianças. Ao encontro desses direitos, entendemos que as experiências lúdicas devem fazer parte de todas as etapas da vida, especialmente na infância. Contudo, muitas vezes, o sistema educacional conspira contra a criança e a infância, impondo tempo e espaços rígidos para aprender, brincar e interagir na escola de Educação Infantil. Marques, Fernandes e Silva (2019) alertam que "o brincar, muitas vezes, é pedagogizado, isto é, colocado a serviço do 'fazer aprender', usado como estratégia para assegurar o sucesso escolar da população infantil" (p. 11). Um importante desafio contemporâneo é educar na perspectiva de uma sociedade amiga do meio ambiente, então, "[...] não basta ensinar as crianças a pensar o mundo, a compreender os processos naturais e culturais. É preciso que elas aprendam a conservá-lo e a preservá-lo" (Tiriba, 2018, p. 186).

Para isso, gestores e professores precisam assumir o compromisso de traçar outros caminhos curriculares para garantir que as crianças vivam plenamente sua infância na escola, garantindo o direito de brincar na/com a natureza. Afinal "As crianças são infinitamente interessadas - e biologicamente programadas para explorar - pelas coisas da natureza, sobre como os materiais se comportam e o que podem fazer com eles" (Associação de Profissionais de Educação da Infância [APEI], 2014, p. 23).

A questão principal do estudo consistiu em saber de que modo as crianças da educação infantil brincam e interagem com os elementos da natureza. $\mathrm{O}$ objetivo do estudo consistiu em conhecer os modos de interações das crianças com os elementos da natureza durante a implementação um espaço de brincadeira no pátio de uma escola pública de educação infantil, localizada em um município da região Sul do Brasil. Tal espaço, denominado de Cozinha de Lama, propiciou o contato direto das crianças com a terra, a água e outros elementos do meio ambiente à sua volta.

A pesquisa qualitativa, do tipo pesquisa-ação, pretendeu mobilizar a comunidade de uma escola pública, localizada no Oeste catarinense, na organização de um espaço onde as crianças pudessem brincar com terra, água e outros elementos da natureza, construindo uma Cozinha de Lama. De acordo com a APEI (2014), a experiência de misturar materiais naturais propicia bem-estar, desenvolvimento e aprendizagens às crianças. Essa proposta foi inspirada na brochura integrante da revista Cadernos de Educação da Infância, n. ${ }^{\circ}$ 101, jan./ abr., 2014, publicada pela Associação de Profissionais de Educação da Infância (APEI), localizada na cidade do Porto, em Portugal.

A cozinha de lama consiste, então, em um espaço externo, construído em parceria com as crianças e com a comunidade educativa, para garantir à infância o direito de brincar na/com a natureza, livre das restrições adultas com relação a sujar-se de lama.

Essa proposta de brincadeira instiga os seres humanos, desde a infância, a se relacionarem de outro modo com o meio ambiente. Fomos ao encontro das palavras de Tiriba (2018) quando afirma que "Se quisermos barrar o processo de destruição que está em curso, precisaremos transformar profundamente nossa maneira de pensar e de sentir, de viver e educar" (p. 213). Estudos dessa pesquisadora apontam para uma possível relação entre a atual situação de degradação ambiental com a desatenção às necessidades e desejos das crianças em espaços educacionais. 
Entendemos que as brincadeiras das crianças com seus pares em uma cozinha de lama podem se constituir em experiências criativas e transdisciplinares de aprendizagem sobre/no/com o meio ambiente.

Com base nas questões apontadas, o estudo buscou escutar e envolver as crianças na reinvenção dos tempos e dos espaços da escola de educação infantil, possibilitando uma maior aproximação delas com o ambiente natural, tendo em vista que a escola é um local privilegiado e dinâmico para a construção de uma relação de amor e respeito para com o meio ambiente.

\section{As crianças e o direito de aprender brincando na/com a natu- reza}

Marques (2013) instiga educadores da infância a indagar e 'se indagar' sobre o quanto as crianças vêm sendo protagonistas em suas brincadeiras e nas escolhas de seus brinquedos: “quero perguntar sobre o 'querer das crianças', ou seja: elas brincam porque querem? Do que querem? Quando querem? Com o que querem? No local que querem? Com quem querem?" (p. 104, grifos da autora). Os ambientes externos são apreciados pelas crianças, contudo, no dia a dia, elas são cerceadas em seus direitos de contato com a natureza e passam grande parte do tempo sentadas nos bancos escolares.

Tiriba (2018) instiga a pensar sobre o modo como a experiência vivida pela criança é pouco valorizada, pois "os adultos funcionam como donos do planejamento, das atividades, do tempo e dos materiais pedagógicos, definindo o que, quando, onde e como as crianças devem aprender" (p. 103).

A perspectiva da Sociologia da Infância vem interrogar o lugar da criança como "um ator social excluído" (Faria; Finco, 2011, p.1), convidando a reconstruir a ideia ocidental e adultocêntrica da criança. Neste sentido,

A sociologia da infância propõe-se a constituir a infância como objecto sociológico, resgatando-a das perspectivas biologistas, que a reduzem a um estado intermédio de maturação e desenvolvimento humano, e psicologizantes, que tendem a interpretar as crianças como indivíduos que se desenvolvem independentemente da construção social das suas condições de existência e das representações e imagens historicamente construídas sobre e para eles. Porém, mais do que isso, a sociologia da infância propõe-se a interrogar a sociedade a partir de um ponto de vista que toma as crianças como objecto de investigação sociológica por direito próprio, fazendo acrescer o conhecimento, não apenas sobre infância, mas sobre o conjunto da sociedade globalmente considerada. (Sarmento, 2005, p.365).

A atual legislação educacional brasileira, alinhada com a perspectiva da Sociologia da Infância, concebe a criança como sujeito histórico, cultural e de direitos. A Constituição da República Federativa do Brasil (1988) estabelece a educação como um direito de todos, contudo, em se tratando de crianças, garantir o seu direito à educação não significa escolarizá-las e mantê-las 'emparedadas' dentro de salas de aula, considerando esse espaço como sendo 'o lugar' de aprendizagens. Conforme a Lei n.. 8.069, de 13 de julho de 1990, que dispõe sobre o Estatuto da Criança e do Adolescente (ECA), a educação e o lazer são direitos das crianças brasileiras que devem ser assegurados pela família, pela sociedade em geral e pelo poder público. 
A atual legislação educacional brasileira, Lei n. ${ }^{9}$ 9.394, de 20 de dezembro de 1996, que estabelece as Diretrizes e Bases da Educação Nacional, atualizada pela Lei n.. 12.796, de 4 de abril de 2013, antecipou a matrícula obrigatória na escola para os quatro anos de idade. Ao encontro do direito de estar na escola e de brincar, as atuais Diretrizes Curriculares Nacionais para a Educação Infantil ${ }^{1}$ estabelecem que todas as propostas pedagógicas de escolas que atendem crianças de zero a cinco anos devem ter como eixos norteadores as interações e as brincadeiras (Resolução n. ${ }^{0}$ 5, 2009). Esse documento ainda destaca que as propostas pedagógicas das escolas devem, entre outras coisas, incentivar e garantir o contato com a natureza (Resolução n. ${ }^{5}$, 2009). Mais recentemente, a Base Nacional Comum Curricular ${ }^{2}$ reafirma o brincar como um dos direitos de aprendizagem na educação infantil (Ministério da Educação [MEC], 2017).

Vimos, então, que brincar na escola é direito amplamente assegurado às crianças na legislação brasileira. Contudo, o modo como esses direitos vêm se desdobrando em práticas nos contextos escolares precisa ser interrogado. Na contramão do que mostra a legislação educacional em vigor, manter as crianças pequenas por longos períodos dentro das salas de aula é prática que vem se naturalizando em muitas escolas brasileiras, com vistas a promover suas aprendizagens.

Contudo, deve-se considerar que os ambientes externos também são contextos ricos de aprendizagens. Nesse sentido, Tiriba (2018) afirma que "Isso requer que nossos planejamentos pedagógicos superem uma visão de educação enquanto processos intramuros, entre paredes" (p. 251).

Goldschmied e Jackson (2006) destacam a urgência de se desconstruir a ideia de pátio escolar como lugar para 'descarregar as energias' entre uma e outra tarefa escolar, mas como local de experiências e aprendizagens. Avisam que "O espaço externo cuidadosamente planejado pode oferecer inúmeras oportunidades, não só para o brincar e as experiências sociais, mas também para o aprendizado em primeira mão, que nenhum livro pode ensinar, sobre as coisas vividas" (Goldschmied e Jackson, 2006, p. 195). No entanto, as autoras lamentam que "Infelizmente, muitas creches são cercadas por áreas retangulares e impessoais de grama e asfalto" (Goldschmied e Jackson, 2006, p. 195). Também Tiriba (n.d.) alerta que "os espaços ao ar livre não são considerados como lugares de aprendizagens escolar sistemáticas, implicando em que, do ponto de vista do planejamento pedagógico, o lado de fora seja, comumente, o lugar do nada" (p. 12).

Tiriba (n.d.) também denuncia as poucas possibilidades que as crianças têm de brincar com pés descalços, de brincar em pátios com grama, terra ou barro, pois o pátio de muitas escolas "não oferece alternativas de brincadeiras de cavar, amontoar, criar e demolir, atividades tão desejadas, que só a terra e a areia propiciam" (p. 8). Nesse sentido, a pesquisadora indaga: "Como aprender a respeitar a natureza se as crianças não convivem com seus elementos?" (Tiriba, n.d., p. 8).

Silva (2010) nos diz que por milhares de anos "a natureza constituiu-se como a primeira grande ludoteca, alimentando dos seus recursos naturais - areia, água, pedras, paus, penas de aves, ramos pendentes das árvores, as folhas de árvores e arbustos, os frutos, o vento etc." (p. 157). Contudo, a sociedade mudou e hoje vivemos um paradoxo no que trata da relação das crianças com a natureza: ao mesmo tempo em que é reconhecida a importância do contato delas com a natureza, também lhes são negadas tais oportunidades. Horn
As Diretrizes Curriculares

Nacionais para a Educação Infantil articulam-se às Diretrizes Curriculares Nacionais da Educação Básica e reúnem princípios, fundamentos e procedimentos definidos pela Câmara de Educação Básica do Conselho Nacional de Educação, para orientar as políticas públicas e a elaboração, planejamento, execução e avaliação de propostas pedagógicas e curriculares de Educação Infantil. (MEC, 2010, p. 11)

2. A Base Nacional Comum Curricular (BNCC) é um documento de caráter normativo que define o conjunto orgânico e progressivo de aprendizagens essenciais que todos os alunos devem desenvolver ao longo das etapas e modalidades da Educação Básica, de modo a que tenham assegurados seus direitos de aprendizagem e desenvolvimento, em conformidade com o que preceitua o Plano Nacional de Educação (PNE). (MEC, 2017, p. 7, grifos do autor) 
(2017) destaca que muitas crianças estão privadas de desfrutar do espaço ao ar livre e de brincar com a natureza. Também Elali (2003) mostrou a partir de seus estudos em escolas infantis que "a área livre mostra-se escassa e dotada de poucos recursos naturais." (p. 315). Entre as razões dessa privação, Horn (2017) elenca a violência urbana, os poucos espaços livres entre os prédios e construções e, também, o modelo tradicional de escola que prioriza a permanência das crianças dentro das salas de aula. Assim, Horn (2017) lamenta a colocação de lajes nos pátios das escolas, encurtamento dos tempos em que as crianças ficam no pátio, bem como a crença de que as atividades com lápis e papel são mais importantes.

A cozinha de lama pode ser um espaço de aproximação entre as crianças e a natureza. Para isso, sugere-se que tenha uma cobertura leve, seja sem piso e paredes laterais, de modo que as crianças possam se proteger do sol forte e dos chuviscos leves; possam pisar na terra e entrar e sair quando quiserem; possam sentir a brisa no rosto e olhar o vento balançando os galhos e as folhas das árvores; possam escutar o canto dos pássaros e observar pequenos insetos. Onde lhes seja permitida uma infinidade de ações tais como:

[...] encher, deitar (derramar), esvaziar, transferir, misturar, mexer, agitar, fazer espuma, escavar, carregar, manipular, moldar, bater, amolecer, riscar, marcar, atirar, espalhar, borrifar, repartir, servir, alisar, selecionar, apanhar, colecionar, recolher, triturar, guarnecer, esmagar, moer, ralar, medir, acrescentar, ferver, peneirar, filtrar, separar, pipetar e decantar. (APEI, 2014, p. 19)

Ao realizarem essas experiências, as crianças operam transformações físicas e mentais, pois "[...] a mistura facilmente se torna o café com açúcar, o bolo de aniversário, sopas e guisados, gelado de muitos sabores, cremes e maquilhagem, bebidas mágicas e poções, feitiços e perfumes" (APEI, 2014, p. 19). Tudo isso livre das restrições impostas pelos adultos.

Em 2014, a APEI publicou uma brochura integrada à revista Cadernos de Educação da Infância, $n^{\circ} 101$, com o propósito de oferecer orientação para criação de uma cozinha de lama. Esse espaço lúdico é propício para misturar terra, água e toda uma variedade de outros materiais naturais e "tem um papel fundacional na infância pelas profundas e infinitas possibilidades de proporcionar bem-estar, desenvolvimento e aprendizagem" (APEI, 2014, p. 6). Segundo esse material:

Uma cozinha de lama inclui elementos da área interior da casa, que é enormemente enriquecida pelo facto especial de esta na rua. As cozinhas de lama funcionam bem durante todo o ano e devem ser vistas como um elemento central a disponibilizar continuamente no exterior. (APEl, 2014, p. 6)

A publicação oferece orientações importantes que devem ser consideradas desde a escolha do local, sua construção, uso e limpeza final. Essas orientações estão sistematizadas de forma sintética na sequência (quadro 1): 
Quadro 1. Sugestões da APEI (2014) para construção de uma cozinha de lama

\begin{tabular}{|c|c|}
\hline $\begin{array}{l}\text { Aspectos a serem } \\
\text { considerados }\end{array}$ & Sugestões da APEI \\
\hline Local & $\begin{array}{l}\text { Preferencialmente que ofereça abastecimento amplo e } \\
\text { acessível aos materiais naturais; }\end{array}$ \\
\hline Espaço & $\begin{array}{l}\text { É importante haver espaço para várias crianças trabalharem } \\
\text { lado a lado ou em colaboração; }\end{array}$ \\
\hline Paredes & $\begin{array}{l}\text { Superfícies verticais baixas em um ou dois lados, } \\
\text { preferencialmente em madeira, para delimitar o espaç, } \\
\text { ornar o ambiente parecido com uma cozinha 'de verdade' e } \\
\text { pendurar utensílios domésticos; }\end{array}$ \\
\hline Entrada e saída & $\begin{array}{l}\text { É necessário que seja fácil de entrar, sair e interagir com } \\
\text { qualquer outra coisa que aconteça no exterior; }\end{array}$ \\
\hline Fonte de água & $\begin{array}{l}\text { Não precisa estar no local, mas na proximidade, de modo que } \\
\text { as crianças possam carregar recipientes com água ou estender } \\
\text { uma mangueira; }\end{array}$ \\
\hline Materiais naturais diversificados & $\begin{array}{l}\text { Cascalhos, pedras, britas, sementes, folhas devem ser } \\
\text { armazenados separadamente em recipientes diversos; }\end{array}$ \\
\hline Materiais de cozinha & $\begin{array}{l}\text { Panelas, frigideiras, bacias, colheres, micoondas (fora de } \\
\text { uso), coadores, jarras, peneiras, escorredores, conchas, } \\
\text { escumadeiras, raladores... }\end{array}$ \\
\hline Superfície para trabalho & $\begin{array}{l}\text { Essa deve ser firme e na altura das crianças para que possam } \\
\text { preparar as comidas de lama; }\end{array}$ \\
\hline Estandes e armários & $\begin{array}{l}\text { Materiais em pequenas cestas ou pendurados de modo que as } \\
\text { crianças possam visualizar facilmente e recolocar nos lugares } \\
\text { após o uso. É desaconselhável o uso de uma "caixa cheia" com } \\
\text { coisas misturadas; }\end{array}$ \\
\hline Higiene e segurança & $\begin{array}{l}\text { Garantir a não contaminação da terra por meio de fezes de } \\
\text { gatos e cães; } \\
\text { Ganchos para pendurar utensílios não podem ficar na altura } \\
\text { dos olhos das crianças; } \\
\text { Lavar as mão com sabão depois das brincadeiras; } \\
\text { Higienizar os utensílios com detergente de cozinha e mantê- } \\
\text { los secos; } \\
\text { Usar avental de plástico ou camiseta velha para, na medida } \\
\text { do possível, proteger a roupa, contudo, é importante ter } \\
\text { cuidado para não coibir as experiências das crianças com } \\
\text { recomendações para não se sujarem. }\end{array}$ \\
\hline
\end{tabular}

Fonte: Adaptado a partir da brochura integrada à revista Cadernos de Educação da Infância, n 101, jan./ abr., 2014.

Como é possível ver na proposta apresentada (quadro 1), para organizar uma cozinha de lama não são necessários materiais exuberantes e caros (APEI, 2014). Nesse processo de organização é recomendado a participação das crianças, sendo que ao adulto cabe viabilizar, "tornando a cozinha disponível (construindo com as crianças a partir das suas próprias especificações) e apoiando o jogo que emerge das crianças". (APEI, 2014, p. 21)

Roni, Alice, Beatriz, Álvaro, José, Viviane, Iara, Gustavo, Carla, Ângela, Bárbara, Ana, Mariane, Jéssica, Roberto, arquitetos da Cozinha de Lama foram parceiros nesta pesquisa. Emprestaram-nos suas expertises infantis, seu tempo, suas ideias, suas palavras, seus risos, suas críticas... Confessamos que foi difícil não apresentar aqui os seus nomes verdadeiros, tendo em vista que eles foram autores de suas falas e produtores do planejamento e construção da Cozinha de Lama. Contudo, nos rendendo às recomendações éticas, que primam pelo anonimato dos participantes, seus nomes foram substituídos aleatoriamente. 


\section{Por onde as crianças nos levaram: o percurso da pesquisa}

A pesquisa foi de cunho qualitativo, do tipo pesquisa-ação, envolvendo a participação de um grupo de crianças no planejamento e organização de um espaço de brincadeira que privilegiou o contato direto delas com os elementos da natureza. A pesquisa-ação consiste em um tipo específico de pesquisa participante e de pesquisa aplicada que supõe intervenção participativa na realidade social. Em se tratando, também, de pesquisa com crianças, foram necessários o cumprimento de determinadas especificidades éticas e metodológicas.

De acordo com Marques (2013), “Pesquisar é sempre um desafio! Mas quando se trata de pesquisar com crianças esse desafio se torna ainda maior" (p. 1), pois os adultos têm o hábito de falar às crianças, mas ainda não construíram o costume de falar 'com' elas e de escutá-las. Essa metodologia reconhece as crianças como sujeitos de pesquisa e não meros objetos de investigação.

Também Cruz (2008) afirma que a escuta das crianças em uma pesquisa científica "[...] tem como pressupostos a crença de que elas têm o que dizer e o desejo de conhecer o ponto de vista delas" (p. 13).

Neste estudo, assumimos o desafio de escutar as crianças naquilo que elas têm a dizer sobre sua relação com os elementos da natureza durante o planejamento, organização e nas brincadeiras na cozinha de lama, pois "desde o momento em que se elaboram as questões a uma criança, se está atribuindo à concepção de sua capacidade, de fazer, pensar, conhecer, atuar, explorar e modificar o que se encontra ao seu redor" (Silva, 2018, p. 41).

A pesquisa foi realizada em uma escola pública de educação infantil, localizada em um bairro da periferia, com um grupo de 17 crianças de quatro a cinco anos de idade, filhas de trabalhadores locais. Essa escola possui espaço físico externo relativamente amplo, contemplando área coberta, pátio aberto e pracinha. Esses espaços são usados diariamente pelas crianças, entretanto, são recorrentes as solicitações das famílias para que as crianças não se sujem de terra durante os momentos em que estão na escola.

A pesquisa foi aprovada pelo Comitê de Ética da universidade a qual estava vinculada. Houve consentimento das famílias mediante assinatura do Termo de Consentimento Livre e Esclarecido para menores de idade e mediante assinatura para uso de imagens. As crianças foram informadas sobre a pesquisa e seu assentimento de participação foi verbal.

No processo de produção das materialidades empíricas, levamos em conta que "Não basta ouvir as crianças. Os educadores, pais e professores, precisam considerar aquilo que elas dizem" (Silva, 2018, p. 27). Seus desenhos, olhares, risos, silêncios, gestos, expressões, choros etc., ao longo de suas interações com os elementos da natureza, tanto quanto o possível, serão dados para análise. As observações registradas e transcrições das cenas de vídeo foram categorizadas e aproximadas ao referencial teórico inicialmente selecionado, para a produção das análises. A escuta das crianças não se restringiu ao momento de planejamento inicial, mas durante todas as etapas da implementação do espaço, como estaremos mostrando a seguir.

Nesse sentido, as atividades realizadas foram documentadas de diferentes formas: caderno de campo, fotografias e vídeos, para posterior análise e categorização. Áudios e vídeos se constituem em ferramentas importantes para o 
pesquisador uma vez que permitem que as cenas sejam revistas dando visibilidade a detalhes que possam ter passado despercebidos durante a realização das atividades.

Inicialmente precisávamos escutar as crianças sobre aquilo que brincavam e pensavam sobre as brincadeiras com terra e água:

“- Eu adoro, mas minha mãe quase sempre não deixa. Ela diz que suja a roupa e fica braba. Bem braba!” (Yasmin);

“- Mas vai dar para brincar no barro, de verdade?” (Valéria);

“- Eu vou gostar muito. Eu sei cuidar um pouco para não sujar a roupa.” (Beatriz);

“- Se for com roupa velha, minha mãe deixa. Eu acho!” (Ana);

“- Às vezes, lá na minha vó, eu brinco com barro.” (Ângela);

“- No meu apartamento, não tem nadinha de barro.” (Jéssica);

“- Eu gosto mais ou menos, porque é ruim ficar toda suja.” (Viviane);

“- Oba! Quero ficar toda 'embelecada' [emelecada].” (Carla);

“- Eu queria, mas acho que minha mãe não vai deixar. Ela sempre diz para não mexer na sujeira." (Gustavo);

“- Eu vou pedir para minha mãe. Tomara que ela deixa.” (Roni);

“- Vou fazer brigadeiros para o aniversário do Homem Aranha." (Álvaro);

“- E eu vou limpar tudinho. Posso trazer vassoura, pano e sabão.” (Aléxia);

“- Eu vou ser o cozinheiro. Vou fazer comida para o meu cachorro.” (José);

“- Eu não gosto muito de barro. Só a areia na praia." (Roberto);

“- Quero brincar de mamãe e fazer comidinhas para minhas filhinhas.” (Mariane).

Embora a maioria das crianças em suas falas evidencie desejo em brincar com barro, elas também evidenciam já terem vivenciado experiências restritivas com relação às brincadeiras com barro. Quanto a esse receio das crianças, Tiriba (2018) argumenta que se sujar faz parte da brincadeira. Segundo ela, "o distanciamento da natureza relaciona-se com a identificação dos elementos do mundo natural com a sujeira, a desorganização, a doença, o perigo" (Tiriba, 2018, p. 145). A autora defende a ideia de desemparedamento das crianças, afinal, elas têm empatia e necessidade de estar com o meio ambiente que as cerca como plantas, animais, pedras, barro, terra, água, ar e vento (Tiriba, 2018). Álvaro e José ainda mostraram estratégias criativas inventadas por eles para se inserirem na brincadeira de fazer 'comidinhas', tida, por muitas pessoas, como brincadeira de menina.

Durante esse momento de escuta das crianças, foram lidas para elas as palavras de Zavalloni (2012) que nos ensinam sobre os Direitos Naturais das Crianças, em epígrafe no início deste texto. 


\section{"Chama a diretora": da elaboração da proposta aos pedidos de autorização}

Esta parte inicial envolveu o planejamento 'com elas' do espaço, bem como a busca por autorização na direção da escola e representantes da Secretaria Municipal de Educação (SME). Na sequência, explicamos ao grupo que iríamos precisar de uma autorização, então, algumas crianças se pronunciaram:

“- Vamos chamar a diretora, aqui!” (Viviane);

“-É, chama a diretora! [disse olhando para a professora]." (Yasmim);

“- E se elas não vierem?” (Eduarda);

“- Então, vamos na diretoria e falamos, ueh! Mostramos o direito escrito [referindose aos Direitos Naturais, de Gianfranco Zavalloni]." (Valéria);

“- Elas vão deixar, eu sei. A gente promete não fazer muita bagunça.” (Viviane).

As crianças tinham consciência de que algumas decisões dependiam de autorizações dos adultos, mas também já tinham alguma ideia sobre seus direitos e estavam dispostas a negociar, caso recebessem resposta negativa.

Com a chegada da diretora, Yasmim foi logo explicando:

“- A gente precisa brincar com barro porque é direito que tem as crianças. Então queremos fazer uma cozinha para brincar de fazer comidas e bolos de barro. Assim [fez movimentos circulares com braços e mãos], pra misturar terra e água, com as mãos. Mas não é de comê de verdade. Lá no pátio. Tu deixa?".

As crianças comemoraram a autorização da gestora da escola e da representante da SME. Elas também se colocaram à disposição para auxiliar e acompanharam as crianças em um passeio pelo pátio para a escolha do melhor local. Uma nova etapa estava começando - mãos à obra!

\section{Construindo a rede: o que iremos precisar? e quem poderá nos ajudar?}

O desafio de educar na perspectiva da sustentabilidade proposto por Tiriba (2018) requer não só que as crianças participem ativamente em ações lúdicas em defesa do meio ambiente, mas que também conte com o apoio de diferentes segmentos da sociedade, resultando em um trabalho em rede.

Tecendo essa rede proposta por Tiriba (2018), construímos coletivamente uma lista de materiais que seriam necessários: 1) materiais de construção (pregos, madeiras...); 2) utensílios de cozinha (panelas, formas, talheres, peneiras, funis, medidores, raladores, espremedores, bacias plásticas de diversos tamanhos, mangueira para puxar água, regadores, peneiras, baldes...);3) materiais naturais. Essa lista era retomada sempre que as crianças lembrassem de algo mais que precisasse ser acrescentado.

Os primeiros parceiros indicados pelas crianças foram suas próprias famílias: "-Meu pai sabe fazer casas e tem uma caixa de ferramentas." (Roni); "-Minha mãe tem um montão de panelas. Vou pedir uma." (Mariane); "- Eu posso 
trazer minhas panelinhas e pratinhos de brinquedo." (Alice). Desse modo, as crianças já planejavam ações concretas para consumar o projeto.

Em conjunto com a professora-pesquisadora, o grupo elaborou um bilhete informando às famílias sobre o projeto. Estas foram convidadas para uma breve reunião no final da tarde para que pudessem conhecer mais detalhes da proposta e serem informadas de que modo poderiam colaborar: coletando elementos da natureza, arrecadando utensílios de cozinha, auxiliando na construção e organização do espaço. As famílias participantes aderiram a ideia, comentaram que seus filhos estavam bastante entusiasmados com o projeto e "- Não falam de outra coisa em casa.".

Uma equipe constituída pela pesquisadora, representante das famílias e crianças da turma fizeram contato com empresários e comerciantes da cidade para solicitar doações de materiais de construção. O projeto foi apresentado e contou com o apoio de três pequenas empresas do bairro para doação dos materiais necessários para a pequena obra.

As crianças também visitaram as demais turmas de educação infantil e anos iniciais da escola divulgando oralmente o projeto e convidando-as a colaborar trazendo materiais como: pinhas, sementes, frascos de diferentes tamanhos para armazenamento de materiais e utensílios de cozinha. A direção da escola acompanhou a turma nesse momento de divulgação, deixando clara a mensagem de que estavam sendo apoiadas pela equipe gestora.

Demais turmas da escola perguntavam se também poderiam brincar na cozinha de lama ou o espaço seria somente para os "pequenos". Foram informadas de que tanto poderiam brincar como ajudar a organizar. Assim, a turma idealizadora do projeto foi conquistando mais e mais parceiros.

\section{"A gente também se embarrava quando criança. Agora é a vez deles!": a construção da cozinha de lama}

As crianças andavam para lá e para cá acompanhando seus familiares na construção da cozinha. Essa empreitada se estendeu por quatro sábados. Algumas famílias, que não podiam vir aos sábados, colaboravam em dias de semana, nos horários em que vinham buscar seus filhos na escola, ao término das aulas. Elas traziam ideias, emprestavam ferramentas, doavam materiais e buscavam ajuda de pessoas qualificadas para a mão de obra. Essas ocasiões ainda foram momentos de aproximação entre pais e professores e, também, de construção de laços de amizade entre as famílias. Enquanto trabalhavam, as famílias conversavam sobre o quanto seus filhos/as estavam entusiasmados e lembravam de seus tempos de criança. Então, um dos pais comentou: "-A gente também se embarrava quando criança. Agora é a vez deles!".

As crianças participavam desses momentos aos sábados carregando as pequenas peças de madeira e alcançando martelos, pregos e alicates. Durante a semana, relatavam para os colegas o que seus pais e elas mesmas haviam feito. Contavam os dias para as brincadeiras na cozinha de lama começarem.

Corroborando Tiriba (2018), acreditamos que é preciso que pais e professores trabalhem juntos na "intenção de educar crianças para que sejam cidadãs planetárias-responsáveis por relações equilibradas entre cultura e natureza." 
(p. 280). A imagem a seguir (figura 1) mostra a fase inicial da construção da Cozinha de Lama:

Figura 1. Fase inicial da construção da Cozinha de Lama

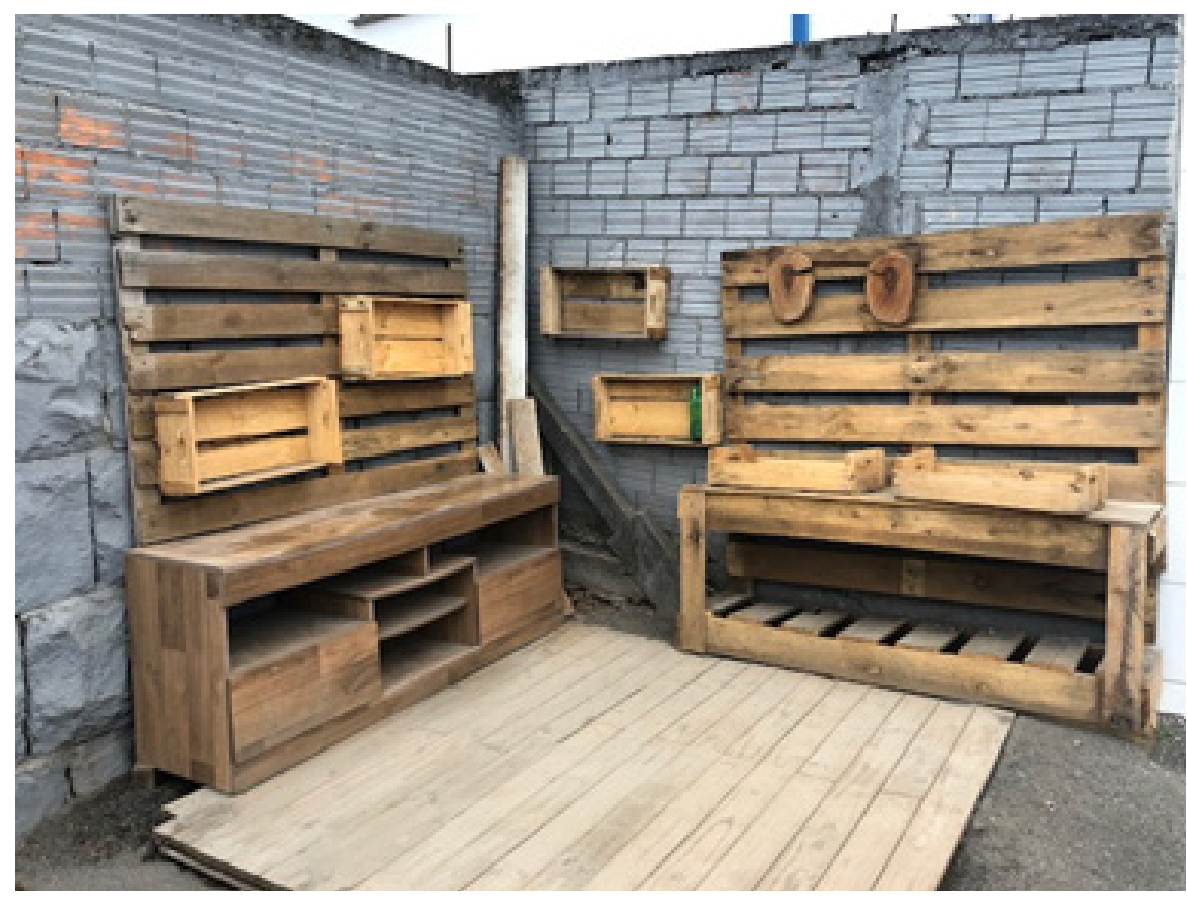

Fonte: Diário de campo

\section{A organização da cozinha pelas crianças: da coleta de mate- riais aos lugares das "coisas"}

Enquanto o espaço era construído, a turma coletava materiais naturais, utensílios de cozinha e frascos para armazenamento dos elementos da natureza. As crianças catavam pelo chão tudo o que lhes parecia interessante: pedrinhas de diferentes tamanhos, cores e formas; folhas verdes e secas; pequenos galhos de árvores; e potes com areia e com terra. Examinavam com curiosidade cada elemento, mostravam umas às outras ao mesmo tempo em que projetavam o que poderiam fazer: "- Vou enfeitar o bolo com essas pedrinhas." (Yasmin) ou "- Dá pra picar essas folhas pra temperar a comida." (Valéria).

Durante os passeios, elas carregavam pequenos sacos confeccionados em algodão cru para armazenar os elementos encontrados no pátio ou no entorno da escola. Tiriba (2018) instiga a olhar para os espaços da educação infantil e seu entorno para identificar o que existia ali: árvores, terra, areia, céu, animais, plantas, o quê? Como as escolas se relacionam com isso que existe de natureza para além dos humanos?

Observamos que existe no pátio da escola uma variedade limitada de elementos da natureza à disposição das crianças. O grupo foi desafiado a continuar a coleta de materiais em suas casas e na vizinhança. Contudo, surgiu a questão: como iríamos armazenar aquele material? As crianças se envolveram na coleta de recipientes para armazenamento, tais como potes de plástico ou de vidro. 
A cada dia, elas se empenhavam na seleção e classificação dos materiais que chegavam.

Após a reunião com as famílias, também começaram a chegar as primeiras panelas, colheres de pau, peneiras, formas de bolo etc., trazidas pelas crianças. A medida que os materiais iam chegando, elas não paravam de perguntar: "-Quando a cozinha vai ficar pronta?".

A lista de convidados foi preparada, os convites foram desenhados e o texto foi construído coletivamente. Foram convidados gestores municipais, gestoras da escola, professores, famílias, pequenos empresários que doaram materais e as crianças das demais turmas da escola. Na semana de inauguração do espaço, as crianças montaram e desmontaram inúmeras vezes as prateleiras da cozinha, escolhendo o melhor lugar para guardar as panelas, bandejas, formas, talheres, panos de limpeza, potes contendo pedras, sementes, folhas...

\section{“Hoje é meu dia mais feliz!": antes e depois da inauguração}

Álvaro chegou dizendo: “- Hoje é meu dia mais feliz.". Ele estava visivelmente alegre e perguntou se já poderia ir ao pátio arrumar a cozinha, explicando: "Quero que esteja bem bonita pra minha mãe ver. Ela vem.". Logo, as demais crianças também foram chegando e estavam tão eufóricas quanto ele.

A inauguração da cozinha de lama, momento tão esperado pelas crianças, foi em uma manhã fria do mês de agosto. $O$ frio e o vento inviabilizaram a brincadeira com lama naquele dia. Apesar disso, optamos por não transferir a data, mas alterar a proposta de atividade. Explicamos às crianças que para evitar possíveis resfriados iríamos fazer comidinhas somente com ingredientes secos. Ainda assim, elas resistiam: "- Mas eu nem tô com frio." (Beatriz); “- Mas a minha mãe deixou!" (Heloísa). Diziam não estar sentindo frio, embora suas roupas de lã, os narizes vermelhos e as mãos geladas dissessem o contrário. Depois de alguns momentos explicando e argumentando, elas acabaram por entender, sendo que ficou combinado que assim que a temperatura subisse, poderiam passar bastante tempo no pátio, brincando com a lama.

"Quanto tempo falta? Quanto tempo falta? Quanto tempo falta?", foram tantas as vezes que fomos interrogadas com essa mesma pergunta, feita pelas crianças. Os convidados foram chegando... Ao dar início, a professora/pesquisadora apresentou o projeto aos convidados e agradeceu aos colaboradores. $\mathrm{Na}$ sequência, as crianças relataram o que haviam feito, quem havia ajudado e convidaram os presentes para conhecer o local. Os convidados foram conduzidos pelas mãos das próprias crianças até o pátio da escola, onde fica a cozinha. Chegando ao local, elas correram para preparar suas misturas (figuras 2 e 3) e logo já estavam servindo 'comidinhas de terra' aos convidados. 
Figura 2. Crianças preparando as comidas

Diálogo entre Ana, Carla e Viviane, enquanto preparavam misturas na Cozinha de Lama, no dia da inauguração:

“- Minha mãe quer provar o meu bolo. Tem que ser rápido porque ela depois vai trabalhar." (Ana).

“- E eu tô fazendo pão pra diretora. Ela pediu." (Carla).

“- Então eu também vou fazer comida pra diretora." (Viviane).

Fonte: Diário de campo

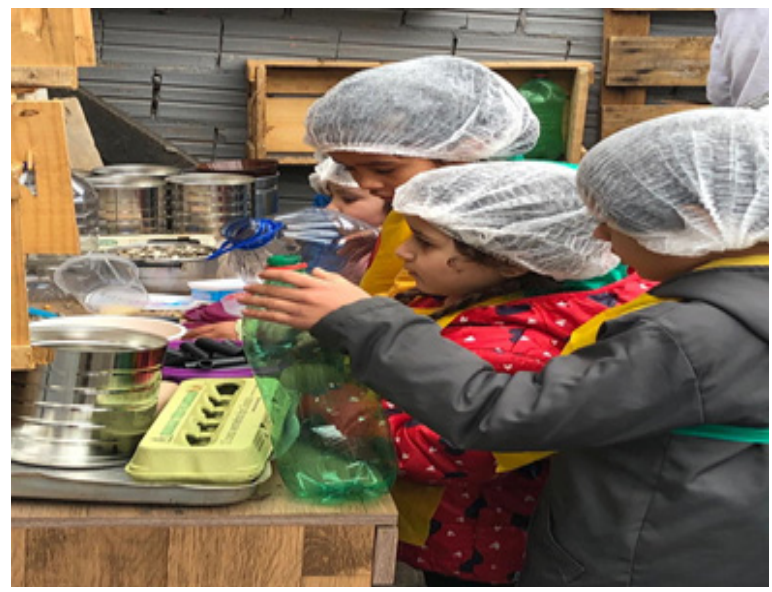

Vimos na imagem (figura 2) e no diálogo entre Ana, Carla e Viviane que elas se sentem apoiadas por suas famílias, professores e gestão escolar para desenvolverem suas experiências na/com elementos da natureza, e isso está relacionado com a participação desses adultos que são referências para elas na construção da Cozinha de Lama. Escutar as crianças sobre aquilo que gostam de brincar no pátio da escola e mobilizar suas famílias para viabilizar esses desejos corresponde àquilo que é recomendado nos documentos legais que orientam a educação brasileira quando destacam as interações e brincadeiras como eixos norteadores das propostas pedagógicas das escolas de educação infantil (Resolução n. ${ }^{\circ}$ 5, 2009), e como direito de aprendizagem das crianças de zero a cinco anos (MEC, 2017).

\section{Figura 3. Crianças medindo os ingredientes}

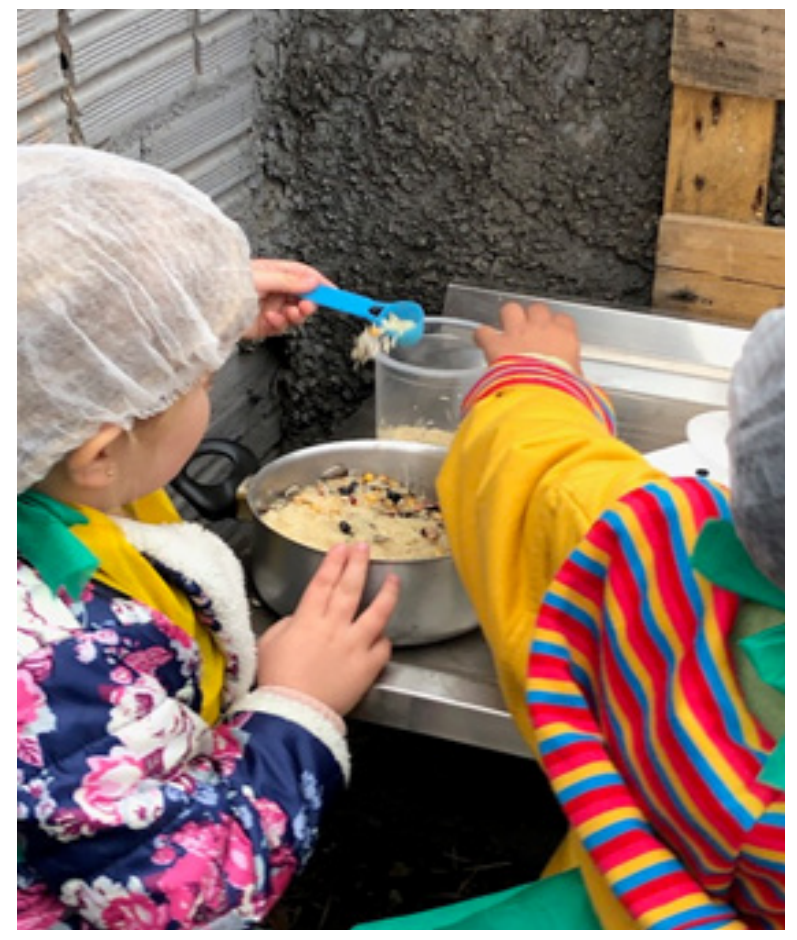

Diálogo entre duas meninas, Mariane e Ângela, enquanto preparavam misturas na Cozinha de Lama, no dia da inauguração:

“- Tô misturando tudo, mas falta botar sal. Três colheres e chega!" (Mariane).

“- Cuida! Tá derramando no chão.” (Ângela).

“ - Vamos pedir pra profe se ela deixa botar água. Só um pouquinho..." (Mariane).

Enquanto Mariane continuava enchendo a panela com colheres de grãos, Ângela se afastou para ir até a professora, retornando em seguida:

“- A profe disse que hoje tá muito frio e que no calor pode brincar com água e fazer comidinha de barro. Eu acho que amanhã vai ser calor." (Ângela). 
Não foi fácil para as crianças compreenderem a restrição de não poderem brincar com água e terra justamente no momento de inauguração do espaço que fora planejado para isso. Em função do vento e do frio, elas permaneceram por cerca de 40 minutos brincando de preparar e servir comidinhas feitas de ingredientes secos. Despediram-se de seus familiares e convidados, agradecendo a presença. Ao retornarem para a sala, estavam visivelmente frustradas, embora compreendessem a situação. Ao fazerem a avaliação do momento da inauguração, elas, de certo modo, recuperaram o entusiasmo rememorando a presença de 'tantos convidados' e o quanto gostaram de suas 'comidas': "- A diretora disse que vem outro dia pra eu fazer pão de barro para ela." (Mariane).

No dia seguinte, a temperatura estava mais amena no meio da manhã e foi possível cumprir com o que havia sido combinado com o grupo: brincar com lama.

Observamos o quanto elas brincaram colaborativamente, emprestando, umas às outras, as panelas, as formas, as colheres... Conversavam sobre suas comidas preferidas, sobre as comidas que suas mães fazem e sobre aquilo que elas mesmas estavam preparando. Quando alguém colocava muita água na massa, elas riam e diziam: "- Fez meleca." Mediam e comparavam as quantidades de água, de terra, de sementes etc. (figuras 4 e 5). Misturavam, amassavam e modelavam muitos docinhos, pastéis, bolos de chocolate, sorvetes e pudins. Comparavam os tamanhos, contavam e recontavam para saber quem havia preparado mais ou menos quantidade de docinhos. Ruim mesmo era somente o momento de parar de brincar. Elas argumentavam: “- Ah, já? Deixa ficar só mais um pouquinho?". Contudo, a hora de arrumar e limpar também era momento de folia. Água, pano e sabão, para ficar tudo bem limpinho.

As crianças da turma do Pré têm muito prazer em dizer a quem quer que encontrem: "- Sabe a cozinha de lama? Fomos nós quem fizemos!".

Figura 4. Misturando com as mãos o bolo de lama

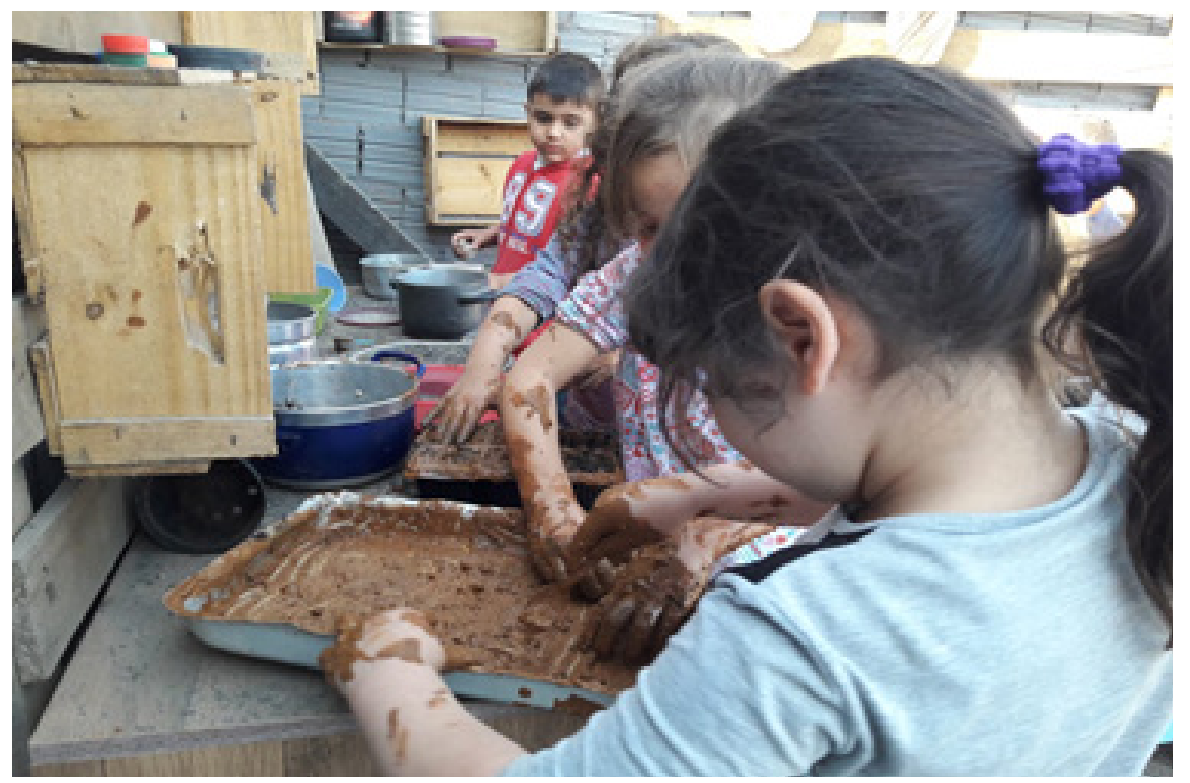

As duas meninas, Alice e Bárbara, estavam dividindo a mesma forma, e a massa de barro estava sendo miturada em quatro mãos. Elas retiravam a massa da forma e distribuíam as porções em pequenos frascos de plástico. Alice, vendo que a colega já havia enchido diversos potinhos, contestou:

“- Não pega tudo, né?! Eu também quero!” (Alice).

“- Mas é de nós duas os bolinhos.” (Bárbara).

Fonte: Diário de campo 
O prazer em misturar terra e água emergiu com intensidade nas experiências das crianças: "- Hoje tá melhor que o outro dia.", disse Alice para Bárbara, que respondeu: "- É porque agora pode brincar de barro.".

Os meninos haviam se reunido todos em um mesmo espaço. Ali se entrelaçavam diferentes contextos de brincadeira. Enquanto alguns diziam estar preparando churrasco, outros misturavam terra e água dentro das formas de bolo ou panelas de alumínio. Roberto, que anteriormente havia afirmado não gostar de barro, mas somente da areia da praia, pouco ousava colocar as mãos no barro, mas participava dando opiniões e contando os 'bolinhos' que eram feitos pelos colegas (figura 5). Contudo, observamos durante as contagens que ele tocava cada bolinho com a ponta do dedo, mostrando suas primeiras aproximações com o barro.

Figura 5. Contando e tocanco no barro com a ponta dos dedos

“- Bah, muita água. Fez meleca. Tem que botar mais terra. Vou pegar." (Roberto).

Então, retornou trazendo um pote de terra e entregou aos colegas. Depois disso, ele foi até o banco onde estavam sendo colocados os bolinhos e com a ponta do dedo tocava em cada um deles contanto:

“-Um, dois, três...” (Roberto).

Fonte: Diário de campo

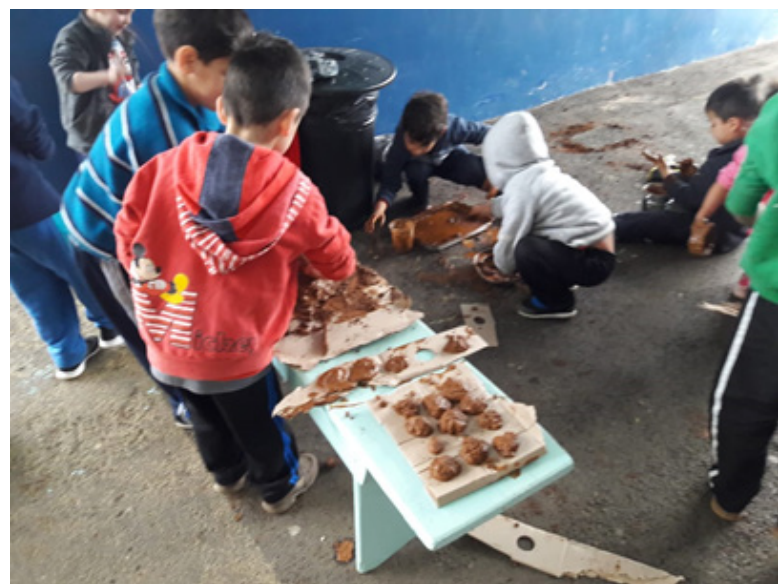

As brincadeiras na cozinha de lama estão inseridas na rotina da educação infantil da escola pesquisada. Além do prazer que proporciona às crianças também oportuniza um novo entendimento de mundo, ajudando a romper com a separação entre seres humanos e natureza. Esse espaço de brincadeira pode ajudar as instituições de educação infantil a materializarem, em seu cotidiano, a aproximação entre as crianças e o mundo natural, seguindo aquilo que ensina Tiriba (n.d., p. 17), ao propor "Derrubar as paredes" como sendo uma condição para aproximação com o mundo natural e consideração para com os desejos do corpo.

Acreditamos que pouco adianta ensinar sobre a natureza por meio apenas de palavras e dentro da sala de aula. Sobre a natureza, as crianças aprendem com intensidade quando estão efetivamente inseridas nela: observando, tocando, cheirando, misturando...

\section{“A gente vai brincar muito aqui!": as considerações finais}

Embora muitas escolas públicas de educação infantil não disponham de um espaço externo amplo e com diversidade de recursos naturais, esse não é o único entrave para garantia dos direitos naturais das crianças. Além da precariedade dos espaços, é comum que elas sejam objetos de restrições com relação a suas brincadeiras com terra, água e barro, para parte de seus familiares e 
professores. Na escola, onde esta pesquisa foi realizada, havia um espaço externo relativamente amplo, mas coexistiam restrições, por parte de professore e familiares, com relação ao uso que as crianças faziam do espaço, considerando as recomendações para que não se 'sujassem' na terra.

A questão principal da pesquisa-ação com crianças consistiu em saber como criar condições de possibilidade para que sejam garantidos os direitos naturais das crianças na escola pública de educação infantil. A implantação de uma Cozinha de Lama, no pátio da escola, foi um estudo gestado nas conversas com as crianças e que mobilizou as famílias e a comunidade escolar.

As falas iniciais das crianças mostravam que elas gostavam de brincar com terra e água. Algumas delas, no entanto, demostravam receio em sujar-se, considerando as diversas situações em que foram repreendidas por 'sujarem' seu corpo, sua roupa e o espaço. Outras, confessaram alguns momentos em que ousaram romper as fronteiras entre o que é tido como 'limpo' e o que é tido como 'sujo'.

Protagonizar o planejamento e a implantação de um espaço que convida a manipular, misturar, cheirar, amassar, picar, peneirar, etc. diferentes elementos da natureza, contando com o apoio e a participação de seus pais e professores, permitiu que elas se sentissem, não somente autorizadas, mas incentivadas a viver tais experiências.

O processo de planejamento e de implementação envolveu a participação ativa das crianças na projeção do espaço, na escolha do local, na listagem de recursos necessários, na busca de parcerias, na coleta de materiais naturais, na construção do mobiliário, na coleta de utensílios domésticos na comunidade e na decoração da cozinha de lama.

As experiências criativas vividas por elas em um contexto de imaginação, quando produziam seus bolos, docinhos e outras 'comidinhas', mostrava o quanto aprendiam experimentando umas com as outras. Também mostrava os modos como buscavam colaborativamente alternativas para resolver situações inusitadas como quando a mistura ficava muito líquida e o colega dizia: "-Tem que botar mais terra!", para possibilitar a modelagem dos docinhos.

Contudo, a relação da criança com a terra e a lama não foi uma vivência que se deu igualmente com todas elas. Há de se considerar que algumas delas precisaram de certo tempo para experimentar, colocando inicialmente somente a ponta do dedo, enquanto outras 'lambuzavam' e 'se labuzavam' sem qualquer tipo de restrição. Nesses momentos, elas estavam nos mostrando que não existe um único modo de elas se relacionarem com os elementos da natureza e, também, que essa relação se dá nas experiências com os pares, em um contexto lúdico e livre de coerções por parte dos adultos.

O envolvimento de professores e famílias na construção desse espaço foi potente para destruir a ideia de que elementos da natureza são 'sujeiras' das quais os adultos precisam proteger as crianças. Ao contrário, é um direito delas, que deve ser garantido pela família, pela escola e pela sociedade como um todo.

Terra, água e outros elementos da natureza são materiais altamente pedagógicos e precisam existir em abundância na vida das crianças, sendo responsabilidade dos adultos criarem condições para isso. 
Ao produzirem as 'melecas', as crianças também estavam produzindo muita imaginação, conhecimento e, especialmente, amor pelos elementos na natureza. Os resultados mostraram que a relação de amor e respeito da criança com a natureza é atravessada tanto pelas experiências lúdicas dela com a terra e a água como pela cumplicidade dos adultos, como mediadores positivos nessa relação.

Existe relação entre a depredação do meio ambiente e o afastamento das crianças dos elementos da natureza, como nos mostra Tiriba (2018). Retomar a relação dos seres humanos com o meio ambiente requer que se comece alimentando ludicamente a relação das crianças com a terra, a água e outros elementos naturais, não somente porque elas precisam, mas porque é direito delas.

O momento desta pesquisa encerrou, mas isso não significa que a temática tenha se esgotado. A Cozinha de Lama, construída no pátio da escola, é temporária. Mas as relações das crianças e suas famílias com a natureza não somente se fortaleceram, como suscitaram outras provocações, afinal, as crianças não são sujeitos abstratos e universais. Não ousamos apresentar verdades absolutas sobre as relações delas com os elementos da natureza. Enquanto pesquisadoras, ainda nos sentimos provocadas a olhar para outros lugares que foram suavemente sinalizados pelas crianças pesquisadas durante a produção dos dados empíricos, entre eles as questões políticas, culturais, sociais e de gênero. Por exemplo, por que algumas meninas participantes da pesquisa expressavam tanto receio em sujar suas roupas ou por que alguns meninos expressavam tanto receio em 'fazer comidinhas'? Mas, como disseram Viviane e Carla: "-A gente vai brincar muito aqui!".

\section{Biografía}

Circe Mara Marques - Pós-doutora em Estudos da Infância pela Universidade do Minho em Braga/PT; Pós-doutora e Doutora em Educação pela Universidade Federal do Rio Grande do Sul. Professora Titular no Programa de Pós-graduação em Educação da Universidade Comunitária da Região de Chapecó-SC, Brasil e no Programa de Pósgraduação em Educação Básica da Universidade Alto Vale do Rio do Peixe-SC, Brasil.

Ana Paula de Lima Pires - Mestre em Eduação Básica pela Univesidade Alto Vale do Rio do Peixe-SC, Brasil. Professora na rede pública Municipal de Caçador-SC, Brasil. 


\section{Q Referências}

Associação de Profissionais de Educação da Infância. (2014). Cadernos de Educação da Infância, 101, jan./abr.

"Cruz, S. H. V. (Org.). (2008). A criança fala: A escuta de crianças em pesquisas. São Paulo: Cortez.

»Elali, G. A. (2003). O ambiente da escola: uma discussão sobre a relação escola-natureza em educação infantil. Estudos de Psicologia, 8(2), 309-319.

» Faria, A. L. G. de e Finco, D. (Orgs.). (2011). Sociologia da infância no Brasil. Campinas/São Paulo: Autores Associados.

》 Goldschmied, E. e Jackson, S. (2006). Educação de o-3 anos: $O$ atendimento em creche (2a ed.; M. Xavier, Trad.). Porto Alegre: Armed.

" Horn, M. G. S. (2017). Brincar e interagir nos espaços da escola infantil. Porto Alegre: Artmed.

" Marques, C. M. (2013). Experiência com bonecas anormais no curso de pedagogia: Construindo modos de ser professora. (tese de doutorado), Universidade Federal do Rio Grande do Sul, Faculdade de Educação, Programa de Pós-Graduação em Educação, Porto Alegre, Brasil.

» Marques, C. M., Fernandes, S. B. e Silva, E. T. (2019). O brincar nos discursos de estudantes de Pedagogia: certezas em suspenso. Pro-posições, 30. Recuperado de http://dx.doi. org/10.1590/1980-6248-2016-0136

"Sarmento, J. (2005). Gerações e alteridade: interrogações a partir da sociologia da infância. Educ. Soc. 26 (91). Recuperado de https://doi.org/10.1590/So10173302005000200003

"Silva, A. N. B. de A. (2010). Jogos, brinquedos e brincadeiras - Trajectos intergeracionais. (tese de doutorado), Universidade do Minho, Instituto de Educação, Braga, Portugal.

"Silva, E. G. da. (2018). Escola 'com' pais: Um projeto para potencializar a parceria entre a família e a escola. (dissertação de mestrado), Universidade Alto Vale do Rio do Peixe, Mestrado Profissional, Programa de Pós-Graduação em Educação Básica, Caçador, Brasil.

" Tiriba, L. (n.d.). Crianças, natureza e educação infantil. Recuperado de http://2greuniao. anped.org.br/trabalhos/trabalho/GTo7-2304--Int.pdf

" Tiriba, L. (2018). Educação Infantil como direito e alegria. Rio de Janeiro/São Paulo: Paz e Terra.

»Zavalloni, G. (2012). A pedagogia do caracol: Por uma escola lenta e não violenta. Americana/SP: Adonis.

\section{Outras fontes consultadas}

" Constituição da República Federativa do Brasil de 1988. Recuperado de http://www.planalto.gov.br/ccivil_03/constituicao/DOUconstituica088.pdf

"Lei n.. 8.069, de 13 de julho de 1990. Dispõe sobre o Estatuto da Criança e do Adolescente e dá outras providências. Recuperado de http://www.planalto.gov.br/ccivil_03/leis/ L8069.htm 
» Lei n.․ 9.394, de 20 de dezembro de 1996. Estabelece as diretrizes e bases da educação nacional. Recuperado de http://www.planalto.gov.br/ccivil_03/leis/l9394.htm

» Lei n.. 12.796 , de 4 de abril de 2013. Altera a Lei n. 9.394, de 20 de dezembro de 1996, que estabelece as diretrizes e bases da educação nacional, para dispor sobre a formação dos profissionais da educação e dar outras providências. Recuperado de http://www. planalto.gov.br/ccivil_03/_ato2011-2014/2013/lei/l12796.htm

» Ministério da Educação. (2010). Diretrizes Curriculares Nacionais para a Educação Infantil. Brasília, DF: MEC, SEB. Recuperado de http://portal.mec.gov.br/dmdocuments/diretrizescurriculares_2012.pdf

" Ministério da Educação. (2017). Base Nacional Comum Curricular (BNCC). Brasília, DF: MEC/SEB. Recuperado de http://basenacionalcomum.mec.gov.br/images/ BNCC_2odez_site.pdf

" Resolução n.ำ 5, de 17 dezembro de 2009. Fixa as Diretrizes Curriculares Nacionais para a Educação Infantil. Recuperado de http://www.seduc.ro.gov.br/portal/legislacao/RESCNEo05_2009.pdf 